\title{
SYNTHESIS AND ANTICANCER ACTIVITY EVALUATION OF SOME NEW DERIVATIVES OF 2-(4-BENZOYL-1-PIPERAZINYL)-QUINOLINE AND 2-(4-CINNAMOYL-1-PIPERAZINYL)-QUINOLINE
}

\author{
KRZYSZTOF P. KUBICA ${ }^{1 *}$, PRZEMYSŁAW P. TACIAK², AGNIESZKA CZAJKOWSKA ${ }^{3}$, \\ ALICJA STOKFISZ-IGNASIAK ${ }^{4}$, RAFAŁ WYREBIAK ${ }^{5}$, PIOTR PODSADNI ${ }^{6}$, \\ IZABELA MŁYNARCZUK-BIAŁY ${ }^{4}$, JACEK MALEJCZYK ${ }^{4}$ and ALEKSANDER P. MAZUREK ${ }^{1,7}$
}

${ }^{1}$ Department of Drug Chemistry, Medical University of Warsaw, Banacha 1, 02-097 Warsaw, Poland ${ }^{2}$ Department of Pharmacodynamics, Center of Preclinical Research and Technology, Żwirki i Wigury 81, 02-091 Warsaw, Poland

${ }^{3}$ Department of Transplantology and Central Tissue Bank, Center of Biostructure Research,

Medical University of Warsaw, Chałubińskiego 5, 02-004 Warsaw, Poland

${ }^{4}$ Department of Histology and Embryology, Center of Biostructure Research,

Medical University of Warsaw, Chałubińskiego 5, 02-004 Warsaw, Poland

${ }^{5}$ Department of Biomaterials Chemistry, Chair of Inorganic and Analytical Chemistry, Medical University of Warsaw, Banacha 1, 02-097 Warsaw, Poland ${ }^{6}$ Department of Drug Technology and Pharmaceutical Biotechnology, Medical University of Warsaw, Banacha 1, 02-097 Warsaw Poland ${ }^{7}$ National Medicines Institute, Chelmska 30/34, 00-725, Warsaw, Poland

\begin{abstract}
In this study, we designed and synthesized twenty new derivatives of 2-(4-benzoyl-1-piperazinyl)quinoline and 2-(4-cinnamoyl-1-piperazinyl)-quinoline with potential anticancer activity. The structures of synthesized compounds were confirmed by ${ }^{1} \mathrm{H}$ and ${ }^{13} \mathrm{C}$ NMR spectroscopy and MS spectrometry. The activity of novel compounds was evaluated in the cell viability assay as well as in the wound healing assay. Presented data show that examined substances have anticancer activity in cell culture. Seven compounds which showed a high rate of cell growth inhibition were selected for further studies. Three of them strongly reduced the growth of B16F10 cells. The novel compounds constitute a good base for further studies and optimization of structure for new therapeutically effective anti-cancerous drugs.
\end{abstract}

Keywords: 2-quinoline, anticancer activity, cell migration assay, cytotoxicity assay

Cancer is a major public health problem in many countries of the world. It is currently the second leading cause of death in the United States and is expected to surpass heart diseases as the leading cause of death in the next few years (1). Therefore there is a continuous need for the development of new compounds with potential anticancer activity.

Carcinogenesis is a complicated process, usually developing over years. The process may be caused by external factors (responsible for up to $80 \%$ of cases), and certain genetic factors. In some types of cancer, the overexpression of specific kinases is one of the basic factors of neoplastic transformation. One example is chronic myeloid leukemia (CML), which is a result of genetic mutation leading to formation of pathological BCR-ABL gene encoding a p210 protein, which shows abnormal, increased tyrosine kinase activity. It is assumed that expression of BCR-ABL is an essential factor for neoplastic transformation in CML. The milestone in the treatment of this type of cancer was introduction of selective kinase inhibitors. In the case of CML, tyrosine kinase inhibitor - Imatinib (Glivec) due to the high efficacy and good tolerability, it became the "gold standard" treatment of patients with CML (2).

\footnotetext{
* Corresponding author: e-mail: krzysztof.pawel.kubica@gmail.com
} 
Protein kinases mediate a selective phosphorylation reaction of specific proteins. Phosphorylation normally leads to changes in conformation of the protein molecule and, as a consequence, results in changes of its activity and ability to interact with other proteins or molecules. Protein kinases are involved in cell signaling and regulation of a variety of cell metabolic pathways. Their activity is under control of a multi-stage regulation, also involving participation of other kinases and protein phosphatases. Phosphorylation of the protein kinase may result in its increased or decreased activity. Kinase activity may also depend on the activity of activatory or inhibitory proteins interacting with regulatory domains of the kinase. Deregulation of kinase activity may be a frequent cause of disease, especially cancer. Thus, kinases appear as a potential target for novel therapeutic agents. Indeed, several inhibitors of protein kinases (e.g., Imatinib, Cabozantinib) have recently been introduced into cancer therapies and other ones (e.g., Patent WO2011130654 A1, Bemaciclib.) are under extensive clinical trials (3-5).

The most important feature of cancer cells is their uncontrolled proliferative potential. Thus DNA synthesis appears as the principal target for anti-cancer therapies. Folic acid is one of the most important coenzymes in the synthesis of nucleic acids, RNA and DNA. Therefore, antifolates are a group of drugs also displaying anti-cancer properties (among others Trimetrexate). Some drugs in this group block binding of folic acid by preventing the synthesis of tetrahydrofolic acid (THF). Other drugs block the synthesis of folic acid. Both types of drugs inhibit cell growth and, as a result, may trigger cell death. These drugs appear to be most effective in highly proliferating cells $(6,7)$.

Analysis of the structure of kinase inhibitors and anti-folate agents has led us to design and synthesis of a series of new combined compounds with potential antitumor activity. In designed structures of the two series of quinoline derivatives shown in Scheme 1 one can see the high structural compliance with a new patented antitumor substance, which is at the stage of clinical phase (8). The protected hydroxyl groups indicate a structural correlation with Trimetrexate, which is a folic acid antagonist. It is worth to pay attention to the quinoline moiety, which is very common fragment in the anticancer drugs that are inhibitors of protein kinases.

\section{EXPERIMENTAL}

\section{CHEMICAL METHODOLOGY}

The main goal of this work was to synthesize the new derivatives of 2-(1-piperazinyl)-quinoline (compounds 9-18) and 4-methyl-2-(1-piperazinyl)-

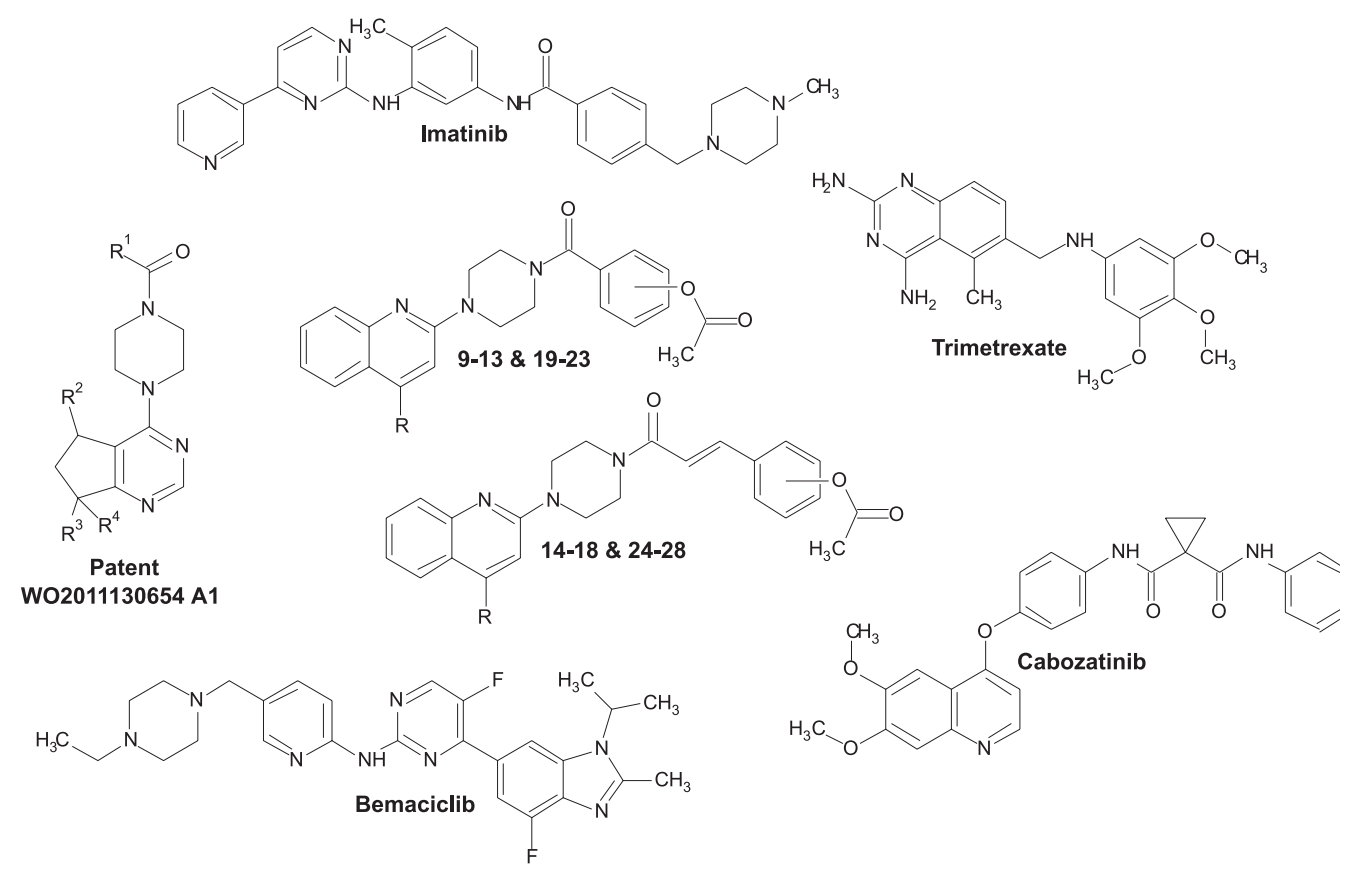

Scheme 1. Structural compliance of new designed derivatives of quinoline with anticancer agents 
quinoline (compounds 19-28). The structure of synthesized compounds was confirmed by ${ }^{1} \mathrm{H}$ and ${ }^{13} \mathrm{C}$ NMR spectroscopy and MS spectrometry.

All chemicals used in the performed reactions were purchased from qualified chemical suppliers. They were of high or highest purity grade and used without any further purification. Melting points (m.p.) which represents the clear point, were determined in open glass capillaries with SRS DigiMelt MPA161 apparatus and are uncorrected. ${ }^{1} \mathrm{H}$ and ${ }^{13} \mathrm{C}$ NMR spectra in solution were recorded at $25^{\circ} \mathrm{C}$ with a Bruker AVANCE III HD (500 MHz). The calculated shielding constants were used as an aid in the assignment of resonances of ${ }^{13} \mathrm{C}$ atoms. Chemical $\delta$ shifts (ppm) were referenced to tetramethylsilane.

The purity of the compounds was routinely checked by thin layer chromatography (TLC) using Kieselgel $60 \quad \mathrm{~F}_{254}$ sheets (Merck, Darmstadt, Germany). Spots were detected under UV light at 254 and $365 \mathrm{~nm}$.

MS analysis was performed with Shimadzu LCMS-2020 mass spectrometer supported by Shimadzu Nexera UHPLC (Japan) system equipped with two pumps (LC-30AD), degasser (DGU-20A5) and autosampler (SIL-30AC). The positive ESI mode was used to produce molecular ions. Data acquisition was performed in Scan mode with interface voltage $4.5 \mathrm{kV}$, interface temperature $350^{\circ} \mathrm{C}$, DL temperature $250^{\circ} \mathrm{C}$, heat block $200^{\circ} \mathrm{C}$ and nitrogen as a nebulizing gas $(1.5 \mathrm{~L} / \mathrm{min})$ and drying gas $(12.0 \mathrm{~L} / \mathrm{min})$. Mobile phase consisted of MS grade water (solvent A) and MS grade methanol (solvent B). The analysis was carried out under the isocratic conditions with solvent A to $B$ ratio $15: 85$ and the flow rate of $0.2 \mathrm{~mL} / \mathrm{min}$.

Scheme and description of the synthesis of 2-(1piperazinyl)-quinoline derivatives

The new compounds $\mathbf{9 - 1 8}$ were synthesized in accordance with a multistep synthetic route shown below (Scheme 2).
The $N$-phenylcinnamamide 1 was synthesized according to the procedure reported in the literature (9). The quinolin-2(1H)-one $\mathbf{2}$ was synthesized according to the procedure also reported in the literature (10). The 2-chloroquinoline $\mathbf{3}$ was synthesized by heating a 2-quinolone with four equivalents of phosphoryl chloride at reflux for two hours, followed by extraction with dichloromethane and evaporation of the solvent. The 2-(piperazin-1-yl)quinoline (Quipazine) 4 was synthesized as per the procedure reported in the literature (11).

\section{Procedure for the preparation of compounds 9-13 (step V in Scheme 2)}

Quipazine 4 (1.00 eq) was dissolved in dichloromethane and stirred for $15 \mathrm{~min}$ at ambient temperature, meanwhile, the triethylamine (1.05 eq) was added. After $15 \mathrm{~min}$ the appropriate benzoyl chloride dissolved in dichloromethane(1.05 eq) was added dropwise (benzoyl chloride for compound $\mathbf{9}$, 3-acetoxybenzoyl chloride for compound 10, 4-acetoxybenzoyl chloride for compound 11, 3,4-diacetoxybenzoyl chloride for compound 12, 3,4,5-triacetoxybenzoyl chloride for compound 13. Chlorides were obtained according to the well-known method - heating with thionyl chloride at $80^{\circ} \mathrm{C}$ for one hour). The course of reaction was monitored by TLC $\left(\mathrm{C}_{6} \mathrm{H}_{14}:\left(\mathrm{CH}_{3}\right)_{2} \mathrm{CO} 2: 1\right)$. After 15 min water was added and the mixture was extracted by $\mathrm{CH}_{2} \mathrm{Cl}_{2}(3 \mathrm{X}$ $20 \mathrm{~mL}$ ). Then, the solvent was evaporated and the remaining product was purified by column chromatography on silica gel (eluent $\mathrm{CH}_{2} \mathrm{Cl}_{2}:\left(\mathrm{CH}_{3}\right)_{2} \mathrm{CO}$ $99: 1)$.

\section{Procedure for the preparation of compounds 14-18 (step VI in Scheme 2)}

Quipazine 4 (1.00 eq) was dissolved in dichloromethane and stirred for $15 \mathrm{~min}$ at ambient temperature, meanwhile, the triethylamine (1.05 eq) was added. After $15 \mathrm{~min}$ the appropriate cinnamoyl

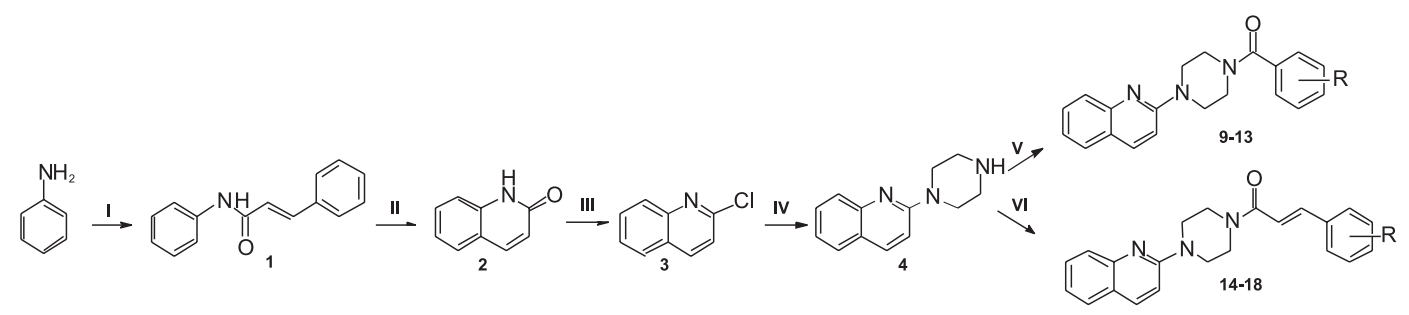

Scheme 2. The synthesis of 2-(4-benzoyl-1-piperazinyl)-quinoline and 2-(4-cinnamoyl-1-piperazinyl)-quinoline. (I) Cinnamoyl chloride, pyridine, $\mathrm{CH}_{2} \mathrm{Cl}_{2}, 1 \mathrm{~h}$; (II) $\mathrm{AlCl}_{3}$; chlorobenzene, $100^{\circ} \mathrm{C}$, 2h; (III) $\mathrm{POCl}_{3}$, reflux, $2 \mathrm{~h}$; (IV) piperazine, $\mathrm{HOCH}_{2} \mathrm{CH}_{2} \mathrm{OH}, 140^{\circ} \mathrm{C}, 4 \mathrm{~h}$; (V) Appropriate benzoyl chloride, triethylamine, $\mathrm{CH}_{2} \mathrm{Cl}_{2}, 0.5 \mathrm{~h}$; (VI) Appropriate cinnamoyl chloride, triethylamine, $\mathrm{CH}_{2} \mathrm{Cl}_{2}, 0.5 \mathrm{~h} ; \mathrm{Compound}$ $9 \mathrm{R}=\mathrm{H} ; 10 \mathrm{R}=3-\mathrm{OCOCH}_{3} ; 11 \mathrm{R}=4-\mathrm{OCOCH}_{3} ; 12 \mathrm{R}=3,4-\mathrm{diOCOCH}_{3} ; 13 \mathrm{R}=3,4,5-$ triOCOCH$_{3} ; 14 \mathrm{R}=\mathrm{H} ; 15 \mathrm{R}=3-\mathrm{OCOCH}$; $16 \mathrm{R}$ $=4-\mathrm{OCOCH}_{3} ; \mathbf{1 7} \mathrm{R}=3,4-\mathrm{diOCOCH}_{3} ; \mathbf{1 8} \mathrm{R}=3-\mathrm{OCOCH}_{3}-4-\mathrm{OCH}_{3}$ 
chloride dissolved in dichloromethane(1.05 eq) was added dropwise (cinnamoyl chloride for compound 14, 3-acetoxycinnamoyl chloride for compound $\mathbf{1 5}$, 4-acetoxycinnamoyl chloride for compound 16, 3,4diacetoxycinnamoyl chloride for compound 17, 3acetoxy-4-methoxycinnamoyl chloride for compound 18. Chlorides were obtained according to the well-known method - heating with thionyl chloride at $80^{\circ} \mathrm{C}$ for one hour). The course of the reaction was monitored by TLC $\left(\mathrm{C}_{6} \mathrm{H}_{14}:\left(\mathrm{CH}_{3}\right)_{2} \mathrm{CO} 2: 1\right)$. After 15 min water was added and the mixture was extracted by $\mathrm{CH}_{2} \mathrm{Cl}_{2}$ ( 3 X $20 \mathrm{~mL}$ ). Then, the solvent was evaporated and the remaining product was purified by column chromatography on silica gel (eluent $\left.\mathrm{CH}_{2} \mathrm{Cl}_{2}:\left(\mathrm{CH}_{3}\right)_{2} \mathrm{CO} 99: 1\right)$.

Scheme and description of the synthesis of 4methyl-2-(1-piperazinyl)-quinoline derivatives

The new compounds $\mathbf{1 9} \mathbf{- 2 8}$ were synthesized according to the procedure showed below (Scheme 3 ).

The $N$-phenylacetoacetamide 5 was synthesized according to the procedure reported in the literature (12). The 4-methylquinolin-2(1H)-one 6 was also synthesized according to the procedure reported elsewhere(13). The 2-chloro-4-methylquinoline 7 was synthesized by heating 4-methylquinolin$2(1 \mathrm{H})$-one with four equivalents of phosphoryl chloride at reflux for two hours, followed by extraction with dichloromethane and evaporation of a solvent. The 4-methyl-2-(piperazin-1-yl)quinoline 8 was synthesized in compliance with the procedure reported in the literature (11).

\section{Procedure for the preparation of compounds 19-23 (Step V in Scheme 3)}

4-Methyl-2-(piperazin-1-yl)quinoline 8 (1.00 eq) was dissolved in dichloromethane and stirred for $15 \mathrm{~min}$ at ambient temperature, meanwhile, the triethylamine (1.05 eq) was added. After $15 \mathrm{~min}$ corresponding benzoyl chloride dissolved in dichloromethane (1.05 eq) was added dropwise (benzoyl chloride for compound 19, 3-acetoxybenzoyl chloride for compound 20, 4-acetoxybenzoyl chloride for compound 21, 3,4-diacetoxybenzoyl chloride for compound 22, 3,4,5-triacetoxybenzoyl chloride for compound 23. Chlorides were obtained according to the well-known method heating with thionyl chloride at $80^{\circ} \mathrm{C}$ for one hour). The course of the reaction was monitored by TLC $\left(\mathrm{C}_{6} \mathrm{H}_{14}:\left(\mathrm{CH}_{3}\right)_{2} \mathrm{CO} 2: 1\right)$. After 15 min water was added and the mixture was extracted by $\mathrm{CH}_{2} \mathrm{Cl}_{2}$ (3 $\mathrm{X} 20 \mathrm{~mL}$ ). Then, the solvent was evaporated and the remaining product was purified by column chromatography on silica gel (eluent $\mathrm{CH}_{2} \mathrm{Cl}_{2}$ : $\left.\left(\mathrm{CH}_{3}\right)_{2} \mathrm{CO} 99: 1\right)$.

\section{Procedure for the preparation of compounds 24-28 (Step VI in Scheme 3)}

4-Methyl-2-(piperazin-1-yl)quinoline $\mathbf{8}$ (1.00 eq) was dissolved in dichloromethane and stirred for $15 \mathrm{~min}$ at ambient temperature, meanwhile, the triethylamine (1.05 eq) was added. After 15 min corresponding cinnamoyl chloride dissolved in dichloromethane (1.05 eq) was added dropwise (cinnamoyl chloride for compound 24, 3-acetoxycinnamoyl chloride for compound 25, 4-acetoxycinnamoyl chloride for compound 26, 3,4-diacetoxycinnamoyl chloride for compound 27, 3-acetoxy-4-methoxycinnamoyl chloride for compound 28. Chlorides were obtained according to the wellknown method - heating with thionyl chloride at $80^{\circ} \mathrm{C}$ for one hour). The course of the reaction was monitored by TLC $\left(\mathrm{C}_{6} \mathrm{H}_{14}:\left(\mathrm{CH}_{3}\right)_{2} \mathrm{CO} 2: 1\right)$. After 15 min water was added and the mixture was extracted by $\mathrm{CH}_{2} \mathrm{Cl}_{2}(3 \mathrm{X} 20 \mathrm{~mL})$. Then, the solvent was evaporated and the remaining product was puri-

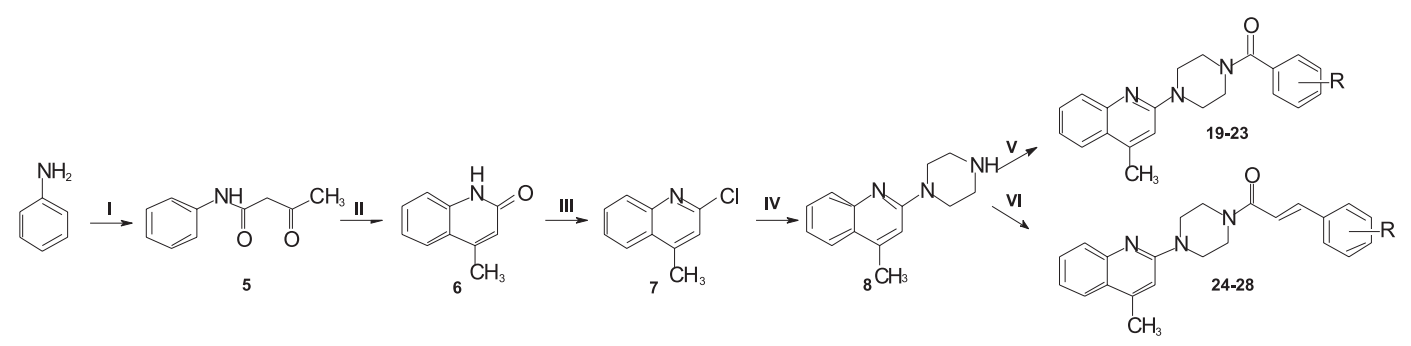

Scheme 3. The synthesis of 4-methyl-2-(4-benzoyl-1-piperazinyl)-quinoline and 4-methyl-2-(4-cinnamoyl-1-piperazinyl)-quinoline. (I) Ethyl acetoacetate, $185^{\circ} \mathrm{C}, 3 \mathrm{~h}$; (II) $\mathrm{H}_{2} \mathrm{SO}_{4}, 100^{\circ} \mathrm{C}$, $1 \mathrm{~h}$; (III) $\mathrm{POCl}_{3}, 120 \mathrm{C}, 2 \mathrm{~h}$; (IV) piperazine, $\mathrm{HOCH}_{2} \mathrm{CH}_{2} \mathrm{OH}, 140^{\circ} \mathrm{C}$, $4 \mathrm{~h}$; (V) Appropriate benzoyl chloride, triethylamine $\mathrm{CH}_{2} \mathrm{Cl}_{2}, 0.5 \mathrm{~h}$; (VI) Appropriate cinnamoyl chloride, triethylamine, $\mathrm{CH}_{2} \mathrm{Cl}_{2}, 0.5 \mathrm{~h}$. Compound: $19 \mathrm{R}=\mathrm{H}$; $20 \mathrm{R}=3-\mathrm{OCOCH}_{3} ; 21 \mathrm{R}=4-\mathrm{OCOCH}_{3} ; 22 \mathrm{R}=3,4-\mathrm{diOCOCH}_{3} ; 23 \mathrm{R}=3,4,5-\mathrm{triOCOCH}_{3} ; 24 \mathrm{R}=\mathrm{H} ; 25 \mathrm{R}=3-\mathrm{OCOCH}_{3} ; 26 \mathrm{R}=4-$ $\mathrm{OCOCH}_{3} ; 27 \mathrm{R}=3,4-\mathrm{diOCOCH}_{3} ; 28 \mathrm{R}=3-\mathrm{OCOCH}_{3}-4-\mathrm{OCH}_{3}$ 
fied by column chromatography on silica gel (eluent $\left.\mathrm{CH}_{2} \mathrm{Cl}_{2}:\left(\mathrm{CH}_{3}\right)_{2} \mathrm{CO} 99: 1\right)$.

\section{Compounds characterization data 2-(4-Benzoyl-1-piperazinyl)-quinoline (9)}

The title compound was obtained in $93 \%$ yield, starting from 4; m.p. $178^{\circ} \mathrm{C}$, Molecular Formula $=$ $\mathrm{C}_{20} \mathrm{H}_{19} \mathrm{~N}_{3} \mathrm{O}$; Molecular Weight $=317.38$;

${ }^{1} \mathrm{H}$ NMR (DMSO-d 6 , $\left.500 \mathrm{MHz}\right): \delta 8.47(\mathrm{~d}, 1 \mathrm{H}$, $J=10.0 \mathrm{~Hz}), 8.43($ br s, $1 \mathrm{H}), 7.94(\mathrm{~d}, 1 \mathrm{H}, J=7.0$ $\mathrm{Hz}), 7.78(\mathrm{t}, 1 \mathrm{H}, J=7.0 \mathrm{~Hz}), 7.56(\mathrm{~d}, 1 \mathrm{H}, J=10.0$ $\mathrm{Hz}), 7.52-7.48$ (m, 6H), $4.12-3.61$ (br m, 8H) ppm; ${ }^{13} \mathrm{C}$ NMR $\left(\mathrm{CDCl}_{3}, 126 \mathrm{MHz}\right): \delta 170.11$, 156.65 , 147.16, 137.29, 135.14, 129.42, 129.24, $128.11,126.80,126.66,126.29,122.85,122.42$, 109.14, 47.00 (br), 45.00, 41.61 (br) ppm. MS-ESI $\mathrm{m} / \mathrm{z}: 318\left(\mathrm{M}^{+}+1,100 \%\right)$.

2-(4-(3-Acetoxybenzoyl)-1-piperazinyl)-quinoline (10)

The title compound was obtained in $82 \%$ yield, starting from 4; m.p. oil, Molecular Formula = $\mathrm{C}_{, 2} \mathrm{H}_{21} \mathrm{~N}_{3} \mathrm{O}_{3}$; Molecular Weight $=375.42$;

${ }^{1} \mathrm{H}$ NMR (DMSO-d $\left.6,500 \mathrm{MHz}\right): \delta 8.07(\mathrm{~d}, 1 \mathrm{H}$, $J=9.0 \mathrm{~Hz}), 7.71\left(\mathrm{dd}, 1 \mathrm{H}, J_{1}=1.5 \mathrm{~Hz}, J_{2}=8.0 \mathrm{~Hz}\right)$, 7.59 (d, 1H, $J=8.0 \mathrm{~Hz}), 7.55-7.50(\mathrm{~m}, 2 \mathrm{H}), 7.35$ $\left(\mathrm{dt}, 1 \mathrm{H}, J_{1}=1.5 \mathrm{~Hz}, J_{2}=7.5 \mathrm{~Hz}\right), 7.26-7.23(\mathrm{~m}$, $4 \mathrm{H}$ ), $3.76-3.47$ (br m, 8H), 2.29 (s, 3H) ppm; ${ }^{13} \mathrm{C}$ NMR (DMSO-d $\left.{ }_{6}, 126 \mathrm{MHz}\right): \delta 169.17,168.12$, 156.62, 150.32, 146.78 (br), 137.79 (br), 137.05, $129.80,128.04,127.49,126.42,124.48,123.15$, 122.80, 122.46 (br), 120.72, 110.31, 46.80 (br), 44.82 (br), 44.35 (br), 41.54 (br), 20.88 ppm. MSESI m/z: $376\left(\mathrm{M}^{+}+1 ; 91,7 \%\right), 334\left(\mathrm{M}^{+}-41,8.3 \%\right)$.

2-(4-(4-Acetoxybenzoyl)-1-piperazinyl)-quinoline (11)

The title compound was obtained in $85 \%$ yield, starting from 4; m.p. $156^{\circ} \mathrm{C}$, Molecular Formula $=$ $\mathrm{C}_{22} \mathrm{H}_{21} \mathrm{~N}_{3} \mathrm{O}_{3}$; Molecular Weight = 375.42;

${ }^{1} \mathrm{H}$ NMR (DMSO-d $\left.\mathrm{D}_{6}, 500 \mathrm{MHz}\right): \delta 8.07(\mathrm{~d}, 1 \mathrm{H}$, $J=9.0 \mathrm{~Hz}), 7.72\left(\mathrm{dd}, 1 \mathrm{H}, J_{1}=1.0 \mathrm{~Hz}, J_{2}=8.0 \mathrm{~Hz}\right)$, $7.59\left(\mathrm{dd}, 1 \mathrm{H}, J_{1}=0.5 \mathrm{~Hz}, J_{2}=8.0 \mathrm{~Hz}\right), 7.55-7.51$ (m, 3H), 7.26-7.22 (m, 4H), $3.76-3.50$ (br m, 8H), 2.30 (s, 3H) ppm; ${ }^{13} \mathrm{C}$ NMR (DMSO-d 6 , $126 \mathrm{MHz}$ ): $\delta$ 169.07, 168.51, 156.86, 151.27, 147.11, 137.56, $133.28,129.50,128.59,127.43,126.08,122.88$, 122.30, 121.95, 110.18, 46.96 (br), 44.73 (br), 44.36 (br), 41.58 (br), 20.88 ppm. MS-ESI m/z: 376 $\left(\mathrm{M}^{+}+1,92.2 \%\right), 334\left(\mathrm{M}^{+}-41,7.8 \%\right)$.

\section{2-(4-(3,4-Diacetoxybenzoyl)-1-piperazinyl)-qui- noline (12)}

The title compound was obtained in $91 \%$ yield, starting from 4; m.p. $75^{\circ} \mathrm{C}$, Molecular Formula $=$ $\mathrm{C}_{24} \mathrm{H}_{23} \mathrm{~N}_{3} \mathrm{O}_{5}$; Molecular Weight $=433.46$;
${ }^{1} \mathrm{H}$ NMR (DMSO-d 6 , $\left.500 \mathrm{MHz}\right): \delta 8.08(\mathrm{~d}, 1 \mathrm{H}, J$ $=9.0 \mathrm{~Hz}), 7.72\left(\mathrm{dd}, 1 \mathrm{H}, J_{1}=1.0 \mathrm{~Hz}, J_{2}=8.0 \mathrm{~Hz}\right), 7.59$ $\left(\mathrm{dt}, 1 \mathrm{H}, J_{1}=1.0 \mathrm{~Hz}, J_{2}=9.0 \mathrm{~Hz}\right), 7.54-7.52(\mathrm{~m}, 1 \mathrm{H})$, $7.43-7.41(\mathrm{~m}, 2 \mathrm{H}), 7.38\left(\mathrm{dd}, 1 \mathrm{H}, J_{1}=2.0 \mathrm{~Hz}, J_{2}=7.0\right.$ $\mathrm{Hz}$ ), $7.26-7.23$ (m, 2H), 3.76-3.51 (br m, 8H), 2.31 (s, 3H), 2.30 (s, 3H) ppm; ${ }^{13} \mathrm{C}$ NMR (DMSO-d 6,126 $\mathrm{MHz}) \delta 168.19,168.15,167.54,156.85,147.11$, $142.92,141.81,137.57,134.12,129.51,127.44$, $126.09,125.62,123.89,122.90,122.83,122.32$, 110.20, 46.92 (br), 44.65 (br), 44.32 (br), 41.61 (br), 20.38 ppm. MS-ESI m/z: $434\left(\mathrm{M}^{+}+1,100 \%\right)$.

\section{2-(4-(3,4,5-Triacetoxybenzoyl)-1-piperazinyl)- quinoline (13)}

The title compound was obtained in $80 \%$ yield, starting from 4; m.p. $173^{\circ} \mathrm{C}$, Molecular Formula $=$ $\mathrm{C}_{26} \mathrm{H}_{25} \mathrm{~N}_{3} \mathrm{O}_{7}$; Molecular Weight $=491.49$;

${ }^{1} \mathrm{H}$ NMR (DMSO-d $\left.{ }_{6}, 500 \mathrm{MHz}\right): \delta 8.08(\mathrm{~d}, 1 \mathrm{H}, J$ $=9.0 \mathrm{~Hz}), 7.72\left(\mathrm{dd}, 1 \mathrm{H}, J_{1}=1.0 \mathrm{~Hz}, J_{2}=8.0 \mathrm{~Hz}\right), 7.59$ $(\mathrm{d}, 1 \mathrm{H}, J=8.0 \mathrm{~Hz}), 7.56-7.52(\mathrm{~m}, 1 \mathrm{H}), 7.38(\mathrm{~s}, 2 \mathrm{H})$, $7.26-7.23$ (m, 2H), $3.76-3.51$ (br m, 8H), 2.34 (s, $3 \mathrm{H}), 2.30(\mathrm{~s}, 6 \mathrm{H}) \mathrm{ppm} ;{ }^{13} \mathrm{C}$ NMR (DMSO-d 6,126 $\mathrm{MHz}): \delta 168.00,167.13,166.77,156.84,147.11$, $143.13,137.58,135.57,133.52,129.51,127.43$, $126.10,122.90,122.33,120.13,110.21,46.90$ (br), 44.64 (br), 44.25 (br), 41.70 (br), 20.38, 19.88 ppm. MS-ESI m/z: $546\left(\mathrm{M}^{+}+55,10.5 \%\right), 530\left(\mathrm{M}^{+}+39,7.4 \%\right)$, $514\left(\mathrm{M}^{+}+23,22.7 \%\right), 492\left(\mathrm{M}^{+}+1,34.5 \%\right), 450\left(\mathrm{M}^{+}-41\right.$, $3.8 \%), 408\left(\mathrm{M}^{+}-83,17.0 \%\right), 366\left(\mathrm{M}^{+}-125,4.1 \%\right)$.

\section{2-(4-Cinnamoyl-1-piperazinyl)-quinoline (14)}

The title compound was obtained in $89 \%$ yield, starting from 4; m.p. $159^{\circ} \mathrm{C}$, Molecular Formula $=$ $\mathrm{C}_{22} \mathrm{H}_{21} \mathrm{~N}_{3} \mathrm{O}$; Molecular Weight $=343.42$;

${ }^{1} \mathrm{H}$ NMR (DMSO-d 6 , $\left.500 \mathrm{MHz}\right): \delta 8.07(\mathrm{~d}, 1 \mathrm{H}$, $J=9.0 \mathrm{~Hz}), 7.76-7.74(\mathrm{~m}, 2 \mathrm{H}), 7.72\left(\mathrm{dd}, 1 \mathrm{H}, J_{1}=\right.$ $\left.1.5 \mathrm{~Hz}, J_{2}=8.0 \mathrm{~Hz}\right), 7.61\left(\mathrm{dt}, 1 \mathrm{H}, J_{1}=0.5 \mathrm{~Hz}, J_{2}=\right.$ $8.5 \mathrm{~Hz}), 7.56(\mathrm{~d}, 1 \mathrm{H}, J=15.5 \mathrm{~Hz}), 7.56-7.52(\mathrm{~m}$, $1 \mathrm{H}), 7.44-7.20(\mathrm{~m}, 8 \mathrm{H}), 3.87-3.74($ br m, 6H) ppm; ${ }^{13} \mathrm{C}$ NMR (DMSO-d $\left.{ }_{6}, 126 \mathrm{MHz}\right): \delta 164.65$, $156.87,147.17,141.71,137.53,135.16,129.49$, $128.79,128.09,127.44,126.42,126.10,122.89$, $122.25,118.22,110.21,45.00$ (br), 44.80 (br), 44.45 (br), 41.52 (br) ppm. MS-ESI m/z: $344\left(\mathrm{M}^{+}+1\right.$, $100 \%)$.

\section{2-(4-(3-Acetoxycinnamoyl)-1-piperazinyl)-quino- line (15)}

The title compound was obtained in $98 \%$ yield, starting from 4; m.p. $118^{\circ} \mathrm{C}$, Molecular Formula = $\mathrm{C}_{24} \mathrm{H}_{23} \mathrm{~N}_{3} \mathrm{O}_{3}$; Molecular Weight $=401.46$;

${ }^{1} \mathrm{H}$ NMR (DMSO-d $\left.\mathrm{d}_{6}, 500 \mathrm{MHz}\right): \delta 8.08(\mathrm{~d}, 1 \mathrm{H}$, $J=9.0 \mathrm{~Hz}), 7.72\left(\mathrm{dd}, 1 \mathrm{H}, J_{1}=1.0 \mathrm{~Hz}, J_{2}=7.5 \mathrm{~Hz}\right)$, $7.61-7.60$ (m, 3H), $7.56-7.53(\mathrm{~m}, 2 \mathrm{H}), 7.47-7.43$ 
$(\mathrm{m}, 1 \mathrm{H}), 7.38(\mathrm{~d}, 1 \mathrm{H}, J=15.5 \mathrm{~Hz}), 7.28(\mathrm{~d}, 1 \mathrm{H}, J=$ $9.0 \mathrm{~Hz}), 7.26-7.23(\mathrm{~m}, 1 \mathrm{H}), 7.17-7.14(\mathrm{~m}, 1 \mathrm{H})$, 3.87 - 3.74 (br m, 8H), 2.30 (s, 3H) ppm; ${ }^{13} \mathrm{C} \mathrm{NMR}$ (DMSO-d $\left.{ }_{6}, 126 \mathrm{MHz}\right): \delta 169.19,164.44,156.86$, $150.92,140.63,137.53,136.81,129.82,129.48$, $128.04,127.43,126.42,126.10,126.05,123.06$, $122.88,120.70,119.33,110.21,45.01$ (br), 44.79 (br), 44.43 (br), 41.55 (br), 20.85 ppm. MS-ESI m/z: $402\left(\mathrm{M}^{+}+1,91.7 \%\right), 360\left(\mathrm{M}^{+}-41,8.3 \%\right)$.

\section{2-(4-(4-Acetoxycinnamoyl)-1-piperazinyl)-quino- line (16)}

The title compound was obtained in $83 \%$ yield, starting from 4; m.p. $166^{\circ} \mathrm{C}$, Molecular Formula = $\mathrm{C}_{24} \mathrm{H}_{23} \mathrm{~N}_{3} \mathrm{O}_{3}$; Molecular Weight $=401.46$;

${ }^{1} \mathrm{H}$ NMR (DMSO-d $\left.{ }_{6}, 500 \mathrm{MHz}\right): \delta 8.07(\mathrm{~d}, 1 \mathrm{H}$, $J=9.0 \mathrm{~Hz}), 7.81(\mathrm{t}, 1 \mathrm{H}, J=2.0 \mathrm{~Hz}), 7.79(\mathrm{t}, 1 \mathrm{H}, J=$ $2.0 \mathrm{~Hz}), 7.72\left(\mathrm{dd}, 1 \mathrm{H}, J_{1}=1.5 \mathrm{~Hz}, \mathrm{~J}_{2}=8.0 \mathrm{~Hz}\right), 7.60$ $\left(\mathrm{dt}, 1 \mathrm{H}, J_{1}=0.5 \mathrm{~Hz}, J_{2}=8.0 \mathrm{~Hz}\right), 7.57-7.52(\mathrm{~m}$, $2 \mathrm{H}), 7.34-7.27$ (m, 2H), $7.26-7.22(\mathrm{~m}, 1 \mathrm{H}), 7.20$ $(\mathrm{t}, 1 \mathrm{H}, J=2.0 \mathrm{~Hz}), 7.18(\mathrm{t}, 1 \mathrm{H}, J=2.0 \mathrm{~Hz}), 3.87-$ 3.74 (br m, 8H), 2.28 (s, 3H) ppm; ${ }^{13} \mathrm{C}$ NMR $\left(\right.$ DMSO$\left._{-}, 126 \mathrm{MHz}\right) \delta 169.11,164.58,156.86$, $151.36,147.16,140.73,137.53,132.87,129.49$, $129.25,127.43,126.10,122.88,122.25,122.23$, 118.33, 110.21, 44.99 (br), 44.79 (br), 44.44 (br), 41.53 (br), 20.89 ppm. MS-ESI m/z: $402\left(\mathrm{M}^{+}+1\right.$, $92.2 \%), 360\left(\mathrm{M}^{+}-41,7.8 \%\right)$.

\section{2-(4-(3,4-Diacetoxycinnamoyl)-1-piperazinyl)- quinoline (17)}

The title compound was obtained in $93 \%$ yield, starting from 4; m.p. $161^{\circ} \mathrm{C}$, Molecular Formula = $\mathrm{C}_{26} \mathrm{H}_{25} \mathrm{~N}_{3} \mathrm{O}_{5}$; Molecular Weight $=459.49$;

${ }^{1} \mathrm{H}$ NMR (DMSO-d 6 , $\left.500 \mathrm{MHz}\right): \delta 8.08(\mathrm{~d}, 1 \mathrm{H}$, $J=9.0 \mathrm{~Hz}), 7.76(\mathrm{~d}, 1 \mathrm{H}, J=2.0 \mathrm{~Hz}), 7.72(\mathrm{dd}, 1 \mathrm{H}$, $\left.J_{1}=1.5 \mathrm{~Hz}, J_{2}=8.0 \mathrm{~Hz}\right), 7.66\left(\mathrm{dd}, 1 \mathrm{H}, J_{1}=2.0 \mathrm{~Hz}\right.$, $\left.J_{2}=6.5 \mathrm{~Hz}\right), 7.60\left(\mathrm{dt}, 1 \mathrm{H}, J_{1}=0.5 \mathrm{~Hz}, J_{2}=8.5 \mathrm{~Hz}\right)$, $7.56-7.52(\mathrm{~m}, 2 \mathrm{H}), 7.36(\mathrm{~d}, 1 \mathrm{H}, J=15.5 \mathrm{~Hz}), 7.32$ $(\mathrm{d}, 1 \mathrm{H}, J=8.5 \mathrm{~Hz}), 7.29$ (d, 1H, $J=9.0 \mathrm{~Hz}), 7.26-$ $7.23(\mathrm{~m}, 1 \mathrm{H}), 3.87$ - 3.74 (br m, 8H), 2.32 (s, 3H), 2.30 (s, 3H) ppm; ${ }^{13} \mathrm{C}$ NMR (DMSO-d $6,126 \mathrm{MHz}$ ): $\delta 168.24,168.17,164.38,156.86,147.14,142.84$, $142.32,139.95,137.53,134.11,129.49,127.43$, $126.88,126.09,123.97,122.88,122.52,122.26$, 119.37, 110.22, 45.01 (br), 44.79 (br), 44.43 (br), 41.55 (br), 20.38, 20.31 ppm. MS-ESI m/z: 460 $\left(\mathrm{M}^{+}+1,100 \%\right)$.

\section{2-(4-(3-Acetoxy-4-methoxycinnamoyl)-1-piper- azinyl)-quinoline (18) \\ The title compound was obtained in $90 \%$ yield, starting from 4; m.p. $152^{\circ} \mathrm{C}$, Molecular Formula = $\mathrm{C}_{25} \mathrm{H}_{25} \mathrm{~N}_{3} \mathrm{O}_{4}$; Molecular Weight $=431.48$;}

${ }^{1} \mathrm{H}$ NMR (DMSO-d $\left.{ }_{6}, 500 \mathrm{MHz}\right): \delta 8.08(\mathrm{~d}, 1 \mathrm{H}$, $J=9.0 \mathrm{~Hz}), 7.72\left(\mathrm{dd}, 1 \mathrm{H}, J_{1}=1.5 \mathrm{~Hz}, J_{2}=8.0 \mathrm{~Hz}\right)$, $7.60\left(\mathrm{dt}, 1 \mathrm{H}, J_{1}=0.5 \mathrm{~Hz}, \mathrm{~J}_{2}=8.5 \mathrm{~Hz}\right), 7.57-7.52$ (m, 3H), $7.36-7.28(\mathrm{~m}, 3 \mathrm{H}), 7.26-7.23(\mathrm{~m}, 1 \mathrm{H})$, $7.13(\mathrm{~d}, 1 \mathrm{H}, J=8.0 \mathrm{~Hz}), 3.89-3.75$ (br m, 8H), 3.89 (s, 3H), 2.27 (s, 3H) ppm; ${ }^{13} \mathrm{C}$ NMR (DMSO-d ${ }_{6}, 126$ $\mathrm{MHz}): \delta 168.48,164.62,156.87,151.11,147.15$, $141.22,140.35,137.54,134.17,129.49,127.44$, $126.10,123.10,122.89,122.27,121.06,118.39$, 111.89, 110.22, 56.03, 45.05 (br), 44.79 (br), 44.47 (br), 41.54 (br), 20.42 ppm. MS-ESI m/z: 432 $\left(\mathrm{M}^{+}+1,91.7 \%\right), 390\left(\mathrm{M}^{+}-41,8.3 \%\right)$.

\section{4-Methyl-2-(4-benzoyl-1-piperazinyl)-quinoline (19)}

The title compound was obtained in $96 \%$ yield, starting from 8; m.p. $133^{\circ} \mathrm{C}$, Molecular Formula $=$ $\mathrm{C}_{22} \mathrm{H}_{21} \mathrm{~N}_{3} \mathrm{O}_{3}$; Molecular Weight $=331.41$;

${ }^{1} \mathrm{H} \mathrm{NMR}\left(\mathrm{CDCl}_{3}, 500 \mathrm{MHz}\right): \delta 7.78\left(\mathrm{dd}, 1 \mathrm{H}, J_{1}\right.$ $\left.=1.0 \mathrm{~Hz}, J_{2}=8.0 \mathrm{~Hz}\right), 7.71(\mathrm{~d}, 1 \mathrm{H}, J=8.5 \mathrm{~Hz}), 7.56$ $-7.52(\mathrm{~m}, 1 \mathrm{H}), 7.45-7.41(\mathrm{~m}, 5 \mathrm{H}), 7.29-7.25(\mathrm{~m}$, $1 \mathrm{H}), 6.83(\mathrm{~d}, 1 \mathrm{H}, J=0.5 \mathrm{~Hz}), 3.92-3.56(\mathrm{br} \mathrm{m}, 8 \mathrm{H})$, $2.60(\mathrm{~d}, 3 \mathrm{H}, J=1.0 \mathrm{~Hz}) \mathrm{ppm} ;{ }^{13} \mathrm{C} \mathrm{NMR}\left(\mathrm{CDCl}_{3}, 126\right.$ $\mathrm{MHz}): \delta 170.11,156.54,147.12,145.08,135.17$, $129.40,128.98,128.10,126.78,126.66,123.22$, 123.06, 122.20, 109.49, 47.06 (br), 44.96, 41.66 (br), 18.81 ppm. MS-ESI m/z: $332\left(\mathrm{M}^{+}+1,100 \%\right)$.

\section{4-Methyl-2-(4-(3-acetoxybenzoyl)-1-piperazinyl)- quinoline (20)}

The title compound was obtained in $85 \%$ yield, starting from 8; m.p. oil, Molecular Formula = $\mathrm{C}_{23} \mathrm{H}_{23} \mathrm{~N}_{3} \mathrm{O}_{3}$; Molecular Weight $=389.45$;

${ }^{1} \mathrm{H}$ NMR (DMSO-d $\left.6,500 \mathrm{MHz}\right): \delta 7.82(\mathrm{dd}$, $\left.1 \mathrm{H}, J_{1}=1.0 \mathrm{~Hz}, J_{2}=8.0 \mathrm{~Hz}\right), 7.59-7.57(\mathrm{~m}, 1 \mathrm{H})$, $7.55-7.50(\mathrm{~m}, 2 \mathrm{H}), 7.35\left(\mathrm{dt}, 1 \mathrm{H}, J_{1}=1.0 \mathrm{~Hz}, J_{2}=\right.$ $7.5 \mathrm{~Hz}), 7.28-7.24(\mathrm{~m}, 3 \mathrm{H}), 7.15(\mathrm{~d}, 1 \mathrm{H}, J=1.0$ $\mathrm{Hz}$ ), $3.75-3.46$ (br m, 8H), 2.57 (d, 3H, $J=1.0 \mathrm{~Hz}$ ), 2.29 (s, 3H) ppm; ${ }^{13} \mathrm{C}$ NMR (DMSO-d $6,126 \mathrm{MHz}$ ): $\delta$ 169.16, 168.07, 156.66, 150.30, 147.13, 145.13, $137.07,129.78,129.25,126.59,124.48,123.79$, $123.13,123.11,122.16,120.72,110.20,46.86$ (br), 44.64 (br), 44.32 (br), 41.52 (br), 20.87, 18.61 ppm. MS-ESI m/z: $390\left(\mathrm{M}^{+}+1,64.1 \%\right), 348\left(\mathrm{M}^{+}-41\right.$, $35.9 \%)$.

\section{4-Methyl-2-(4-(4-acetoxybenzoyl)-1-piperazinyl)- quinoline (21)}

The title compound was obtained in $88 \%$ yield, starting from 8; m.p. $147^{\circ} \mathrm{C}$, Molecular Formula = $\mathrm{C}_{23} \mathrm{H}_{23} \mathrm{~N}_{3} \mathrm{O}_{3}$; Molecular Weight $=389.45$;

${ }^{1} \mathrm{H}$ NMR (DMSO-d $\left.6,500 \mathrm{MHz}\right): \delta 7.82(\mathrm{dd}$, $\left.1 \mathrm{H}, J_{1}=1.5 \mathrm{~Hz}, J_{2}=8.0 \mathrm{~Hz}\right), 7.58\left(\mathrm{dd}, 1 \mathrm{H}, J_{1}=1.5\right.$ $\left.\mathrm{Hz}, J_{2}=7.0 \mathrm{~Hz}\right), 7.55-7.51(\mathrm{~m}, 3 \mathrm{H}), 7.28-7.22$ 
(m, 3H), 7.14 (s, 1H), $3.75-3.50$ (br m, 8H), 2.57 $(\mathrm{s}, 3 \mathrm{H}), 2.30(\mathrm{~s}, 3 \mathrm{H}) \mathrm{ppm} ;{ }^{13} \mathrm{C} \mathrm{NMR}\left(\mathrm{CDCl}_{3}, 126\right.$ $\mathrm{MHz}): \delta 169.81,169.17,157.04,151.82,147.67$, $145.64,133.16,129.52,128.74,127.36,123.77$, $123.60,122.76,121.89,110.02,47.69$ (br), 45.48, 42.35 (br), 21.23, 19.35 ppm. MS-ESI m/z: 390 $\left(\mathrm{M}^{+}+1,100 \%\right)$.

\section{4-Methyl-2-(4-(3,4-diacetoxybenzoyl)-1-piper- azinyl)-quinoline (22)}

The title compound was obtained in $94 \%$ yield, starting from 8; m.p. $151^{\circ} \mathrm{C}$, Molecular Formula $=$ $\mathrm{C}_{25} \mathrm{H}_{25} \mathrm{~N}_{3} \mathrm{O}_{5}$; Molecular Weight $=447.48$;

${ }^{1} \mathrm{H}$ NMR (DMSO-d $\left.{ }_{6}, 500 \mathrm{MHz}\right): \delta 7.83(\mathrm{dd}$, $\left.1 \mathrm{H}, J_{1}=1.0 \mathrm{~Hz}, J_{2}=8.5 \mathrm{~Hz}\right), 7.59-7.57(\mathrm{~m}, 1 \mathrm{H})$, $7.55-7.52(\mathrm{~m}, 1 \mathrm{H}), 7.43-7.41(\mathrm{~m}, 2 \mathrm{H}), 7.38(\mathrm{dd}$, $\left.1 \mathrm{H}, J_{1}=2.5 \mathrm{~Hz}, J_{2}=6.0 \mathrm{~Hz}\right), 7.28-7.25(\mathrm{~m}, 1 \mathrm{H})$, $7.15(\mathrm{~d}, 1 \mathrm{H}, J=0.5 \mathrm{~Hz}), 3.75-3.51($ br m, 8H), 2.58 (d, 3H, $J=1.0 \mathrm{~Hz}) 2.31(\mathrm{~s}, 3 \mathrm{H}), 2.30(\mathrm{~s}, 3 \mathrm{H}) \mathrm{ppm}$; ${ }^{13} \mathrm{C}$ NMR (DMSO-d $\left.6,126 \mathrm{MHz}\right) \delta 168.20,168.14$, $167.52,156.66,147.14,145.14,142.92,141.80$, $134.11,129.26,126.59,125.63,123.89,123.80$, $123.13,122.84,122.17,110.21,46.98$ (br), 44.56 (br), 44.33 (br), 41.75 (br), 20.39, 18.62 ppm. MSESI m/z: $448\left(\mathrm{M}^{+}+1,100 \%\right)$.

\section{4-Methyl-2-(4-(3,4,5-triacetoxybenzoyl)-1-piper- azinyl)-quinoline (23)}

The title compound was obtained in $91 \%$ yield, starting from 8; m.p. $99^{\circ} \mathrm{C}$, Molecular Formula = $\mathrm{C}_{27} \mathrm{H}_{27} \mathrm{~N}_{3} \mathrm{O}_{7}$; Molecular Weight $=505.52$;

${ }^{1} \mathrm{H}$ NMR (DMSO-d $\left.{ }_{6}, 500 \mathrm{MHz}\right): \delta 7.83(\mathrm{dd}$, $\left.\left.1 \mathrm{H}, J_{1}=1.0 \mathrm{~Hz}\right), J_{2}=8.5 \mathrm{~Hz}\right), 7.60-7.58(\mathrm{~m}, 1 \mathrm{H})$, $7.55-7.52(\mathrm{~m}, 1 \mathrm{H}), 7.38(\mathrm{~s}, 2 \mathrm{H}), 7.28-7.25(\mathrm{~m}$, $1 \mathrm{H}), 7.16(\mathrm{~d}, 1 \mathrm{H}, J=0.5 \mathrm{~Hz}), 3.75-3.50$ (br m, $8 \mathrm{H})$, $2.58(\mathrm{~d}, 3 \mathrm{H}, J=1.0 \mathrm{~Hz}), 2.34(\mathrm{~s}, 3 \mathrm{H}), 2.30(\mathrm{~s}, 6 \mathrm{H})$ ppm; ${ }^{13} \mathrm{C}$ NMR (DMSO-d $6,126 \mathrm{MHz}$ ): $\delta$ 168.00, $167.13,166.75,156.64,147.13,145.15,143.11$, $135.56,133.50,129.26,126.60,123.79,123.14$, 122.18, 120.14, 110.22, 46.92 (br), 44.48 (br), 44.28 (br), 41.76 (br), 20.39, 19.88, 18.60 ppm. MS-ESI $\mathrm{m} / \mathrm{z}: 506\left(\mathrm{M}^{+}+1,2.4 \%\right), 464\left(\mathrm{M}^{+}-41,15.3 \%\right), 422$ $\left(\mathrm{M}^{+}-83,69.7 \%\right), 380\left(\mathrm{M}^{+}-125,12.6 \%\right)$.

\section{4-Methyl-2-(4-cinnamoyl-1-piperazinyl)-quino- line (24)}

The title compound was obtained in $90 \%$ yield, starting from 8; m.p. oil, Molecular Formula = $\mathrm{C}_{23} \mathrm{H}_{23} \mathrm{~N}_{3} \mathrm{O}$; Molecular Weight = 357.49;

${ }^{1} \mathrm{H} \mathrm{NMR}\left(\mathrm{CDCl}_{3}, 500 \mathrm{MHz}\right): \delta 7.80\left(\mathrm{dd}, 1 \mathrm{H}, J_{1}\right.$ $\left.=1.0 \mathrm{~Hz}, \mathrm{~J}_{2}=8.0 \mathrm{~Hz}\right), 7.74-7.71(\mathrm{~m}, 2 \mathrm{H}), 7.39-$ $7.35(\mathrm{~m}, 5 \mathrm{H}), 7.30-7.27(\mathrm{~m}, 2 \mathrm{H}), 6.93(\mathrm{~d}, 1 \mathrm{H}, J=$ $15.5 \mathrm{~Hz}), 6.85(\mathrm{~d}, 1 \mathrm{H}, J=1.0 \mathrm{~Hz}), 3.89-3.75(\mathrm{br}$ $\mathrm{m}, 8 \mathrm{H}), 2.62(\mathrm{~d}, 3 \mathrm{H}, J=1.0 \mathrm{~Hz}) \mathrm{ppm} ;{ }^{13} \mathrm{C} \mathrm{NMR}$
$\left(\mathrm{CDCl}_{3}, 126 \mathrm{MHz}\right): \delta 165.83,143.27,135.34$, $129.87,129.60,128.97,128.68,127.96,127.76$, $127.33,127.11,123.78,123.68,122.75,117.04$, 109.96, 45.79 (br), 45.49 (br), 45.12 (br), 42.09 (br), 19.43 ppm. MS-ESI m/z: $358\left(\mathrm{M}^{+}+1,100 \%\right)$.

\section{4-Methyl-2-(4-(3-acetoxycinnamoyl)-1-piper- azinyl)-quinoline (25)}

The title compound was obtained in $85 \%$ yield, starting from 8; m.p. $139^{\circ} \mathrm{C}$, Molecular Formula = $\mathrm{C}_{25} \mathrm{H}_{25} \mathrm{~N}_{3} \mathrm{O}_{3}$; Molecular Weight $=415.48$;

${ }^{1} \mathrm{H} \mathrm{NMR}\left(\mathrm{CDCl}_{3}, 500 \mathrm{MHz}\right): \delta 7.79\left(\mathrm{dd}, 1 \mathrm{H}, J_{1}\right.$ $\left.=1.0 \mathrm{~Hz}, J_{2}=8.0 \mathrm{~Hz}\right), 7.73(\mathrm{~d}, 1 \mathrm{H}, J=8.0 \mathrm{~Hz}), 7.68$ $(\mathrm{d}, 1 \mathrm{H}, J=15.5 \mathrm{~Hz}), 7.57-7.54(\mathrm{~m}, 1 \mathrm{H}), 7.40-$ $7.38(\mathrm{~m}, 1 \mathrm{H}), 7.30-7.26(\mathrm{~m}, 2 \mathrm{H}), 6.91(\mathrm{~d}, 1 \mathrm{H}, J=$ $15.5 \mathrm{~Hz}), 6.84(\mathrm{~d}, 1 \mathrm{H}, J=1.0 \mathrm{~Hz}), 3.87-3.75$ (br $\mathrm{m}, 8 \mathrm{H}), 2.62(\mathrm{~d}, 3 \mathrm{H}, J=1.0 \mathrm{~Hz}), 2.32$ (s, 3H) ppm; ${ }^{13} \mathrm{C}$ NMR $\left(\mathrm{CDCl}_{3}, 126 \mathrm{MHz}\right): \delta 169.47,165.45$, $156.96,151.14,145.72,142.10,136.95,129.95$, $129.57,128.61,127.29,125.73,123.75,123.65$, $122.95,122.72,120.48,118.15,109.92,45.75$ (br), 45.40 (br), 45.09 (br), 42.08 (br), 21.25, 19.39 ppm. MS-ESI m/z: $416\left(\mathrm{M}^{+}+1,91.3 \%\right), 374\left(\mathrm{M}^{+}-41\right.$, $8.7 \%)$.

4-Methyl-2-(4-(4-acetoxycinnamoyl)-1-piperazinyl)-quinoline (26)

The title compound was obtained in $88 \%$ yield, starting from 8; m.p. $147^{\circ} \mathrm{C}$, Molecular Formula = $\mathrm{C}_{25} \mathrm{H}_{25} \mathrm{~N}_{3} \mathrm{O}_{3}$; Molecular Weight $=415.48$;

${ }^{1} \mathrm{H}$ NMR $\left(\mathrm{CDCl}_{3}, 500 \mathrm{MHz}\right): \delta 7.79\left(\mathrm{dd}, 1 \mathrm{H}, J_{1}\right.$ $\left.=1.0 \mathrm{~Hz}, \mathrm{~J}_{2}=8.5 \mathrm{~Hz}\right), 7.73(\mathrm{~d}, 1 \mathrm{H}, J=8.5 \mathrm{~Hz}), 7.70$ $(\mathrm{d}, 1 \mathrm{H}, J=15.5 \mathrm{~Hz}), 7.57-7.53(\mathrm{~m}, 3 \mathrm{H}), 7.29-7.26$ $(\mathrm{m}, 1 \mathrm{H}), 7.13(\mathrm{t}, 1 \mathrm{H}, \mathrm{J}=2.0 \mathrm{~Hz}), 7.11(\mathrm{t}, 1 \mathrm{H}, J=2.0$ $\mathrm{Hz}), 6.88(\mathrm{~d}, 1 \mathrm{H}, J=15.0 \mathrm{~Hz}), 6.84(\mathrm{~d}, 1 \mathrm{H}, J=0.5$ $\mathrm{Hz}), 3.87-3.38$ (br m, 8H), $2.62(\mathrm{~d}, 3 \mathrm{H}, J=1.0 \mathrm{~Hz}$ ), 2.31 (s, 3H) ppm; ${ }^{13} \mathrm{C} \mathrm{NMR}\left(\mathrm{CDCl}_{3}, 126 \mathrm{MHz}\right): \delta$ $169.31,165.59,156.96,151.73,147.71,145.66$, $142.12,133.06,129.55,129.00,127.29,123.74$, 123.64, 122.69, 122.15, 117.20, 109.91, 45.73 (br), 45.40 (br), 45.05 (br), 42.05 (br), 21.24, 19.38 ppm. MS-ESI m/z: $416\left(\mathrm{M}^{+}+1,91.7 \%\right), 374\left(\mathrm{M}^{+}-41,8.3 \%\right)$.

\section{4-Methyl-2-(4-(3,4-diacetoxycinnamoyl)-1-piper- azinyl)-quinoline (27)}

The title compound was obtained in $95 \%$ yield, starting from 8; m.p. $131^{\circ} \mathrm{C}$, Molecular Formula = $\mathrm{C}_{27} \mathrm{H}_{27} \mathrm{~N}_{3} \mathrm{O}_{5}$; Molecular Weight $=473.52$;

${ }^{1} \mathrm{H} \mathrm{NMR}\left(\mathrm{CDCl}_{3}, 500 \mathrm{MHz}\right): \delta 7.79\left(\mathrm{dd}, 1 \mathrm{H}, J_{1}\right.$ $\left.=1.0 \mathrm{~Hz}, J_{2}=7.5 \mathrm{~Hz}\right), 7.73(\mathrm{~d}, 1 \mathrm{H}, J=8.5 \mathrm{~Hz}), 7.65$ $(\mathrm{d}, 1 \mathrm{H}, J=15.5 \mathrm{~Hz}), 7.57-7.54(\mathrm{~m}, 1 \mathrm{H}), 7.41(\mathrm{dd}$, $\left.1 \mathrm{H}, J_{1}=2.0 \mathrm{~Hz}, J_{2}=8.5 \mathrm{~Hz}\right), 7.38(\mathrm{~d}, 1 \mathrm{H}, J=2.0$ $\mathrm{Hz}), 7.30-7.26(\mathrm{~m}, 1 \mathrm{H}), 7.22(\mathrm{~d}, 1 \mathrm{H}, J=8.0 \mathrm{~Hz})$, $6.86(\mathrm{~d}, 1 \mathrm{H}, J=15.5 \mathrm{~Hz}), 6.84(\mathrm{~d}, 1 \mathrm{H}, J=1.0 \mathrm{~Hz})$, 
3.86 (br s, 4H), 3.76 (br s, 4H), 2.62 (d, 3H, $J=0.5$ $\mathrm{Hz}$ ), 2.31 (s, 3H), 2.30 (s. 3H) ppm; ${ }^{13} \mathrm{C}$ NMR $\left(\mathrm{CDCl}_{3}, 126 \mathrm{MHz}\right): \delta 168.26,168.16,165.30$, $156.93,145.71,143.12,142.48,141.34,134.25$, $129.57,128.60,127.27,126.40,123.94,123.74$, 123.64, 122.71, 122.35, 118.24, 109.92, 45.74 (br), 45.39 (br), 45.10 (br), 42.07 (br), 20.76, 20.74, 19.38 ppm. MS-ESI m/z: $474\left(\mathrm{M}^{+}+1,80.6 \%\right), 390$ $\left(\mathrm{M}^{+}-83,19.4 \%\right)$.

\section{4-Methyl-2-(4-(3-acetoxy-4-methoxycinnamoyl)- 1-piperazinyl)-quinoline (28)}

The title compound was obtained in $90 \%$ yield, starting from 8; m.p. $86^{\circ} \mathrm{C}$, Molecular Formula = $\mathrm{C}_{26} \mathrm{H}_{27} \mathrm{~N}_{3} \mathrm{O}_{4}$; Molecular Weight $=445.51$;

${ }^{1} \mathrm{H} \mathrm{NMR}\left(\mathrm{CDCl}_{3}, 500 \mathrm{MHz}\right): \delta 7.80\left(\mathrm{dd}, 1 \mathrm{H}, J_{1}\right.$ $\left.=1.0 \mathrm{~Hz}, J_{2}=8.0 \mathrm{~Hz}\right), 7.73(\mathrm{~d}, 1 \mathrm{H}, J=8.0 \mathrm{~Hz}), 7.67$ $(\mathrm{d}, 1 \mathrm{H}, J=15.0 \mathrm{~Hz}), 7.57-7.54(\mathrm{~m}, 1 \mathrm{H}), 7.29-$ $7.26(\mathrm{~m}, 1 \mathrm{H}), 7.16\left(\mathrm{dd}, 1 \mathrm{H}, J_{1}=0.5 \mathrm{~Hz}, J_{2}=2.0 \mathrm{~Hz}\right.$, $\left.J_{3}=8.5 \mathrm{~Hz}\right), 7.10(\mathrm{~d}, 1 \mathrm{H}, J=2.0 \mathrm{~Hz}), 7.05(\mathrm{~d}, 1 \mathrm{H}, J$ $=8.0 \mathrm{~Hz}), 6.86(\mathrm{~d}, 1 \mathrm{H}, J=15.5 \mathrm{~Hz}), 6.85(\mathrm{~d}, 1 \mathrm{H}, J$ $=1.0 \mathrm{~Hz}), 3.89-3.76($ br m, $8 \mathrm{H}), 3.88(\mathrm{~s}, 3 \mathrm{H}), 2.62$ $(\mathrm{d}, 3 \mathrm{H}, J=1.0 \mathrm{~Hz}), 2.32(\mathrm{~s}, 3 \mathrm{H}) \mathrm{ppm} ;{ }^{13} \mathrm{C} \mathrm{NMR}$ $\left(\mathrm{CDCl}_{3}, 126 \mathrm{MHz}\right): \delta 168.96,165.59,156.98$, $151.43,147.71,145.70,142.56,141.02,134.35$, $129.57,127.30,123.75,123.65,123.29,122.72$, $120.55,117.33,111.67,109.93,56.07,45.71$ (br), 45.41 (br), 45.06 (br), 42.10 (br), 20.77, 19.39 ppm. MS-ESI m/z: $446\left(\mathrm{M}^{+}+1,100 \%\right)$.

\section{BIOLOGICAL METHODOLOGY}

\section{Reagents}

Synthesized substances were dissolved in DMSO (Sigma-Aldrich) to obtain $50 \mathrm{mM}$ stock solutions and kept in $4^{\circ} \mathrm{C}$ prior to use. Stock solutions were diluted in cell culture medium to get the planned concentration of compounds (5, 50 and 500 $\mu \mathrm{mol} / \mathrm{L})$. Final concentration of DMSO never exceeded $2 \%$.

\section{Cell culture}

Novel derivatives of quinoline were tested in four cell lines: NIH3T3 (mouse fibroblasts), B16F10 (mouse melanoma), HeLa (human cervical cancer) and HL-60 (human leukemia). The kinase inhibitor U0126 (Promega) was used as an internal validation to compare the anticancer effect of novel compounds to a well-defined one. Cells were maintained in standard conditions (95\% humidity, 5\% $\mathrm{CO}_{2}, 37^{\circ} \mathrm{C}$ ) and cultured in appropriate medium (DMEM for NIH3T3, B16F10, HeLa and RPMI for HL-60). The media were supplemented with $10 \%$ fetal bovine serum and $1 \%$ antibiotic-antimycotic
(Sigma). Cells were passaged three times per week using $0.25 \%$ trypsin solution. All cell lines were from ATCC (The Global Bioresource Center).

\section{Cytotoxicity assays}

Cytotoxic/cytostatic effects induced by novel quinoline derivatives were determined by crystal violet viability test (14). Briefly, cells were seeded overnight at a density 10000 cells per well in 96well plates (Nest) and then, after overnight incubation, the relevant compounds in a range of concentrations $(5,50$ and 500 ěmol/L) were added to cell culture. After 48-hour incubation cell viability was evaluated as described elsewhere (15). Absorbance was measured on a plate reader (Fluorostar, BMC) at $\lambda=570 \mathrm{~nm}$. Each assay consisted of three replicates and was repeated at least twice. Data were expressed as percentages of control cells, calculated from the absorbance corrected for background.

\section{In vitro cell migration and invasion assay}

The transwell cell migration assay was performed to study whether and how the novel compounds inhibit tumor cell migration (16). Cell migration test was validated for B16F10 cells as described in (17), thus this cell line was investigated in cell migration assay. The test was performed for all compounds.

In this assay, examined cells were seeded in a 24-well tissue culture plate (Falcon) and grown to $50-60 \%$ confluence followed by addition of compounds or vehicle at $50 \mu \mathrm{mol} / \mathrm{L}$. Then a scratch of approximately $700 \mu \mathrm{m}$ wide was generated using a pipette tip and the wound closure (cell migration) was recorded using the time-lapse microscopy (JuLi, NanoEnTek). Snapshot images were taken at the beginning and after 24 hours at the end of the experiment.

\section{Statistical analysis}

In the statistical analysis, Student's t-test was used to evaluate viability data. Test results were considered significant at a p-value $<0.05$.

\section{RESULTS AND DISCUSSION}

\section{Cytotoxicity assays}

The perfect cancer therapy could carry out two important functions: selectively target tumor cells and produce cytotoxic effects. To study these aspects of our quinoline derivatives, viability test with crystal violet assay was performed as described in Biological Methodology. We used tumor cells to study cytotoxic/cytostatic effects and non-tumor 
cells to evaluate tumor selectivity of our compounds.

Viability assay was performed in three tumor cell lines conducted from three different tumors, melanoma, cervix cancer, and lymphoma, respectively and in NIH3T3 fibroblasts as non-cancer cells.

The results of crystal violet assay are displayed as relative viability ( $\%$ of the untreated controls). From twenty compounds examined at 5-500 $\mu \mathrm{mol} / \mathrm{L}$ one representative concentration was selected.

All examined substances displayed dosedependent effects, however for more transparency of the results we displayed results for $50 \mu \mathrm{mol} / \mathrm{L}$, concentrations because results of the two other concentrations ( 5 and $500 \mu \mathrm{mol} / \mathrm{L}$, respectively) do not give any important additional information. Thus data displayed in Figure 1 are obtained for particular substances $(50 \mu \mathrm{mol} / \mathrm{L})$ that is indicated in the $\mathrm{X}$ axis description.

B16F10 melanoma cell line turned out to be the most sensitive for cytotoxic/cytostatic effects of novel quinoline derivatives. Seventeen from 20 examined compounds demonstrated significant viability reduction. In particular, compounds 10, 18 and 25 left less than $20 \%$ of viable cells. The viability reduction between $75-50 \%$ was obtained for compounds labeled: 12, 13, 15, 16, 17, 19, 21, 22, 26, 27,28 . The viability reduction in the range of $20-$ $50 \%$ was observed for $\mathbf{9}, \mathbf{1 1}, \mathbf{2 0}$. No significant viability reduction was observed for 14, 23, 24,

HeLa cervical cancer cell line demonstrated significant viability reduction for 12 novel compounds. The viability reduction between 25 and $50 \%$ was obtained for substances numbered 10, 12, 16, 19, 22, 26. The viability reduction between $75-50 \%$ yielded for compounds labeled 15, 18, 21, 25, 27, 28. No significant viability reduction was observed for 9, 11, 13, 14, 17, 20, 23, 24.
The HL-60 leukemia cell line was sensitive towards novel compounds to the lesser extent. IC of $75 \%$ was reached for compound number 18. All other active compounds, in particular enumerated: $13,14,15,17,19,20,21,24,25,26$ and 28 reduced the viability within the range of $10-45 \%$. No significant viability reduction was found for $9,10,11,12$, 16, 22, 23, 27.

The normal NIH3T3 fibroblasts were significantly sensitive towards all compounds in exception of $9, \mathbf{1 4}, \mathbf{2 4}$, for those no significant viability reduction was evaluated.

Summarizing, the compound profiling yielded potent antimelanoma compounds. It is particularly noteworthy that the compounds $9,10,12,16,18$ were found to elicit promising cytotoxicity against B16F10 cells and to be melanoma selective. Table 1 shows a compilation of all results, indicating $\mathbf{1 8}$ as a leading structure for future modeling.

\section{Cell migration assay}

To establish the effect of compounds on metastasis, we investigated whether the drugs interfere with cell motility using a wound healing assay. The test was performed for all compounds in mouse melanoma B16F10 cells. The data are displayed for compounds inhibiting cell migration. The other compounds did not affect cell migration or eliminated most of the treated cells (making the measurement of the diameter of the wound impossible) and they were not shown. Consistently, data from the wound healing assay revealed that fewer cells migrated from the wound edge to the center space upon treatment with compounds 11, 13, 17, 21, 22, 26, 27. The results are shown in Figure 2. White lines on photos show the frame of the wound before incubation. Analyzing the confluence and morphology of cells around the scratch area we can observe some cytopathic effects and diminished cell density

Table 1. Summary of results from cell viability assay: numbers indicate given compounds, U0126 - kinase inhibitor.

\begin{tabular}{|c|c|c|c|c|c|}
\hline \multicolumn{2}{|c|}{} & \multicolumn{4}{|c|}{ Range of viable cells left after incubation with compounds (at 50 $\mu \mathrm{mol} / \mathrm{L})$} \\
\hline Type of cell line & Cell line & $<20 \%$ & $20 \%-50 \%$ & $51 \%-75 \%$ & No viability reduction \\
\hline Melanoma & B16F10 & $10,18,25$ & $\begin{array}{c}12,13,15,16,17,19, \\
21,22,26,27,28, \mathbf{U 0 1 2 6}\end{array}$ & $9,11,20$ & $14,23,24$ \\
\hline $\begin{array}{c}\text { Cervix } \\
\text { cancer }\end{array}$ & Hela & & $\begin{array}{c}15,18,21, \\
25,27,28\end{array}$ & $\begin{array}{c}10,12,16,19, \\
22,26, \mathbf{U 0 1 2 6}\end{array}$ & $9,11,13,14,17$, \\
\hline Leukemia & HL-60 & & 18 & $\begin{array}{c}13,14,15,17,19, \\
20,21,24,25,26,28\end{array}$ & $\begin{array}{c}9,10,11,12,16,22, \\
23,27, \mathbf{U 0 1 2 6}\end{array}$ \\
\hline $\begin{array}{c}\text { Non-tumor } \\
\text { fibroblasts }\end{array}$ & NIH-3T3 & $22, \mathbf{U 0 1 2 6}$ & $\begin{array}{c}11,12,13,15,17,18, \\
21,25,27,28\end{array}$ & $10,16,19,20,23,26$ & $9,14,24$ \\
\hline
\end{tabular}



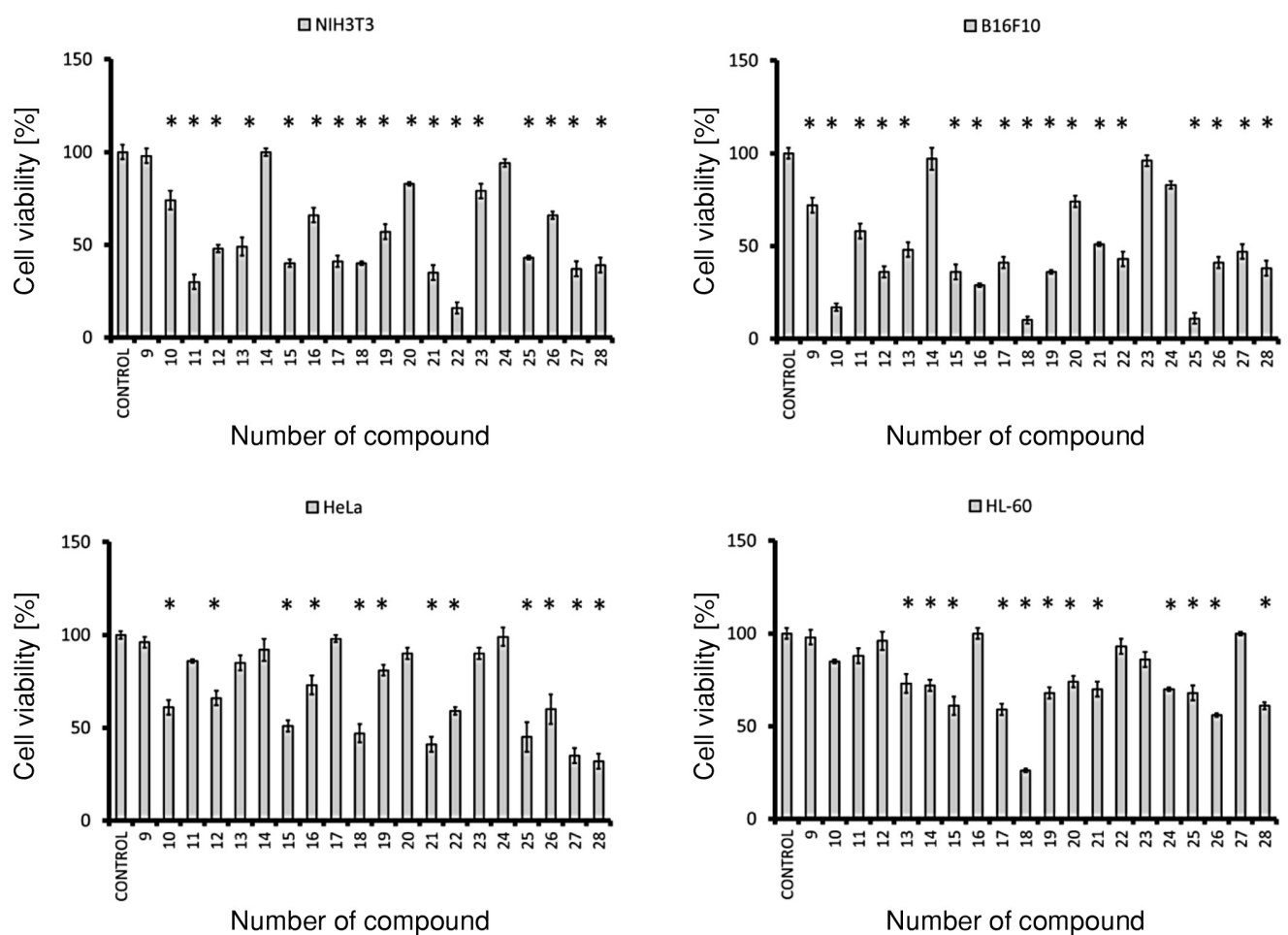

Figure 1. Cell viability test for $50 \mu \mathrm{mol} / \mathrm{L}$ concentration. NIH3T3 cells, B16F10 cells, Hela cells, HL-60 cells. * Significantly different from the controls ( $p<0.05$ in Student`s t-test)

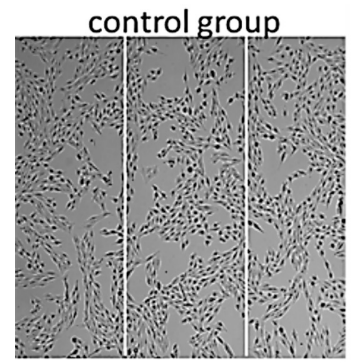

21

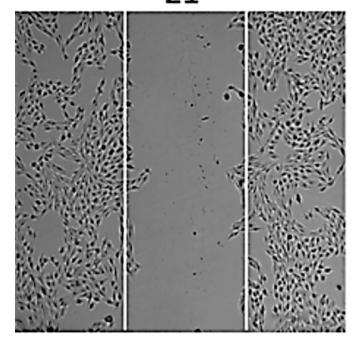

13

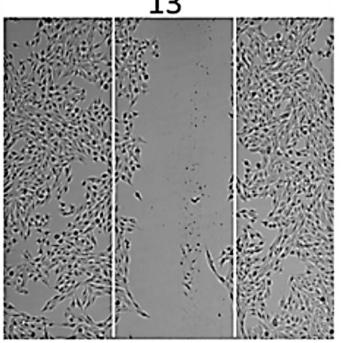

26
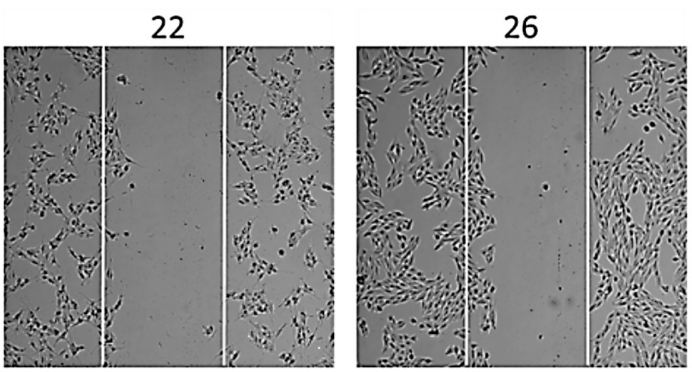

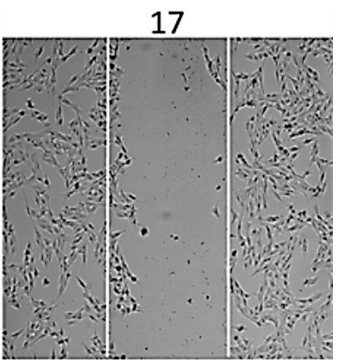

27

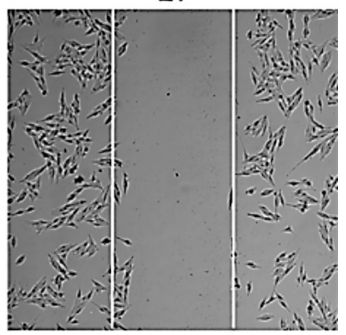

Figure 2. Selected photos of wound healing test on B16F10 cells for $50 \mu \mathrm{mol} / \mathrm{L}$ concentration after $24 \mathrm{~h}$ of incubation 
induced by examined substances compared to the control group. The wound healing assay enables examination of two processes: proliferation and migration. The result of wound healing assay is an outcome of these two independent processes. The given compound inducing moderate antiproliferative but strong antimigratory effect yields the same result in this test as a higher cytotoxic one with lower antimigratory activity. As it is shown in Figure 2, this is the case for compounds 11, 13, 21. In the presence of these compounds cells from the wound free region proliferated comparative like in the control group (Fig. 2), however strong migration inhibition is observed. While compounds 17, 22, 26, 27 disabled both migration and proliferation, giving the same wound diameter but reduced cell number in the wound-free region (Fig. 2) as well as in crystal violet examination (Fig. 1 upper right panel) in comparison to the control.

\section{CONCLUSION}

In conclusion, we synthesized twenty new derivatives of 2-(1-piperazinyl)-quinoline and 4methyl-2-(1-piperazinyl)-quinoline. Those compounds show many structural analogies to medicines, which are widely used in anticancer treatment. Structure of new compounds was confirmed by ${ }^{1} \mathrm{H}$ and ${ }^{13} \mathrm{C}$ NMR spectra, as well as the MS data. The biological activity of twenty novel compounds was tested on tumor cell lines. Tests on non-cancer cells were also performed. Obtained data show that examined substances possess anticancer activity, moreover in in vitro tests they were less toxic for mouse fibroblasts. Activity against tumor depends on the type of cancer, results showed that mouse melanoma cells are the most sensitive to new quinoline derivatives, whereas human leukemia cells are the most resistant among tested lines. Seven compounds selected for further studies showed the highest rate of cell inhibition. Moreover, three of them strongly inhibited the cell growth in B16F10 cells.

\section{REFERENCES}

1. Siegel R.L., Miller K.D., Jemal A.: CA Cancer J. Clin. 65, 5 (2015).

2. Izydorczyk O., Tybor J., Robak T.: Postępy Hig. Med. Dośw. 60, 490 (2006).

3. Mariaule G., Belmont P.: Molecules. 19, 14366 (2014).

4. Adrian F., Dierks C., Grey N., Markus W.: Patent WO2009091476 A1 (2009).

5. Ubersax J.A., Ferrell Jr J.E.: Nat. Rev. Mol. Cell. Biol. 8, 530 (2007).

6. Gonen N., Assaraf Y.G.: Drug Resist. Updat. 15, 183 (2012).

7. Hagner N., Joerger M.: Cancer Manag. Res. 2, 293 (2010).

8. Punnoose E.: Patent WO2011130654 A1 (2011).

9. Saraf A.S., Simonyan A.V.: Pharm. Chem. J. 26, 598 (1992).

10. Cao X-H., Pan X., Zhou P-J., Zou J-P., Asekun O.T.: Chem. Commun. 50, 3359 (2014).

11. Asagarasu A., Matsui T., Hayashi H., Tamaoki S., Yamauchi Y. et al.: J. Med. Chem. 53, 7549 (2010).

12. Jaggavarapu S.R., Kamalakaran A.S., Jalli V.P., Gangisetty S.K., Ganesh M.R., Gaddamanugu G.: J. Chem. Sci. 126, 187 (2014).

13. Deshmukh M.B., Chavan P.B.: J. Indian. Chem. Soc. 68, 573 (1991).

14. Feoktistova M., Geserick P., Leverkus M.: Cold Spring Harb. Protoc. 4, 343 (2016).

15. Młynarczuk-Biały I., Roeckmann H., Kuckelkorn U., Schmidt B., Umbreen S., Gołąb J. et al.: Cancer Res. 66, 7598 (2006).

16. Liang C-C., Park A.Y., Guan J-L.: Nat Protoc. 2, 329 (2007).

17. Justus C.R., Leffler N., Ruiz-Echevarria M., Yang L.V.: Jove-J Vis Exp 51046, (2014).

Received: 04.06. 2017 